\title{
Body imaging
}

S K Misser, ${ }^{1}$ MB ChB, FCRad (D) SA; D B Steer, ${ }^{2}$ FCS (SA), FRCS (C); S Purcell, ${ }^{3}$ FCPath (SA)

${ }^{1}$ Lake Smit and Partners, Durban, South Africa

${ }^{2}$ Alberlito Hospital, Ballito KwaZulu-Natal, South Africa

${ }^{3}$ Hainsworth, Purcell and Associates, Durban, South Africa

Corresponding author: S K Misser (misser@lakesmit.co.za)

口7.20 A 38-year-old woman presented with a painful left aramedian infra-umbilical abdominal wall mass. She was a keen athlete and otherwise well. The following 口. ultrasound images and MRI sequences (after gadolinium administration) were obtained. Describe the relevant imaging findings and formulate the most appropriate clinical diagnosis.
Please submit your response to misser@lakesmit.co.za not later than 15 January 2014. The winning respondent will receive a R1 000 award from the RSSA. A detailed diagnosis and discussion will be presented in the next issue of the SAJR.

S Afr J Rad 2013;17(4):156-157. DOI:10.7196/SAJR.1021 


\section{QUIZ CASE}

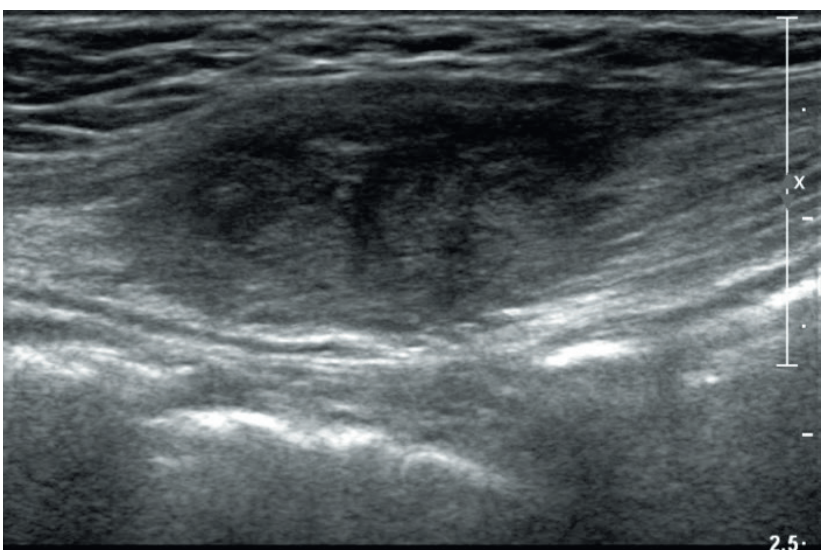

Fig. 1. Sagittal B-mode sonar image.

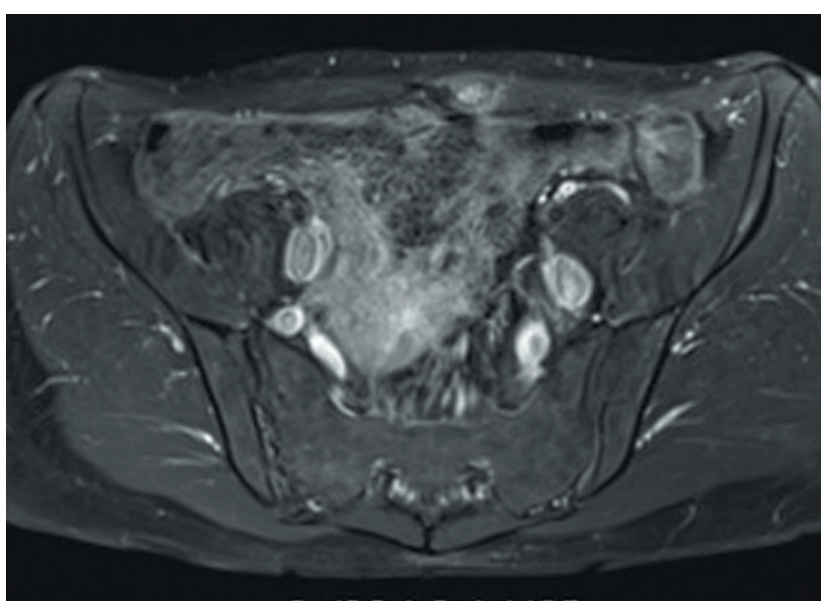

Fig. 3. Axial post-Gd T1-weighted image through lesion.

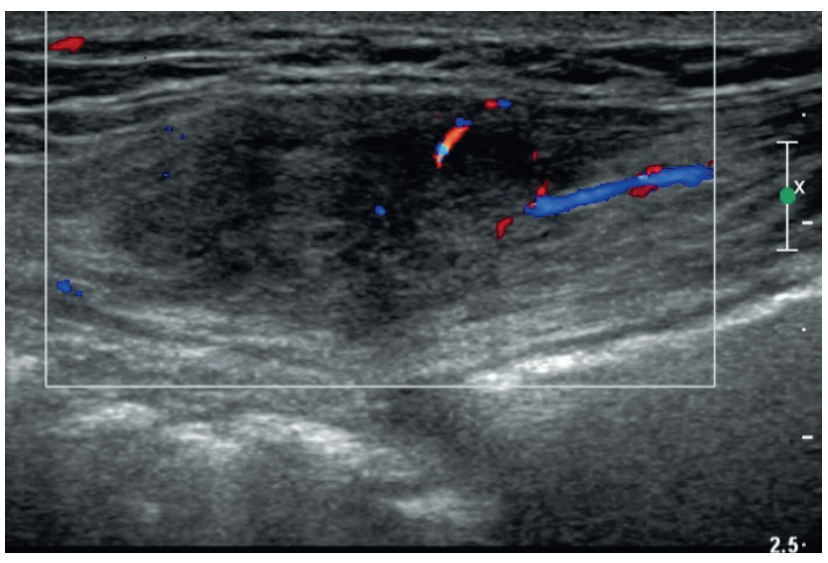

Fig. 2. Sagittal colour duplex sonar image.

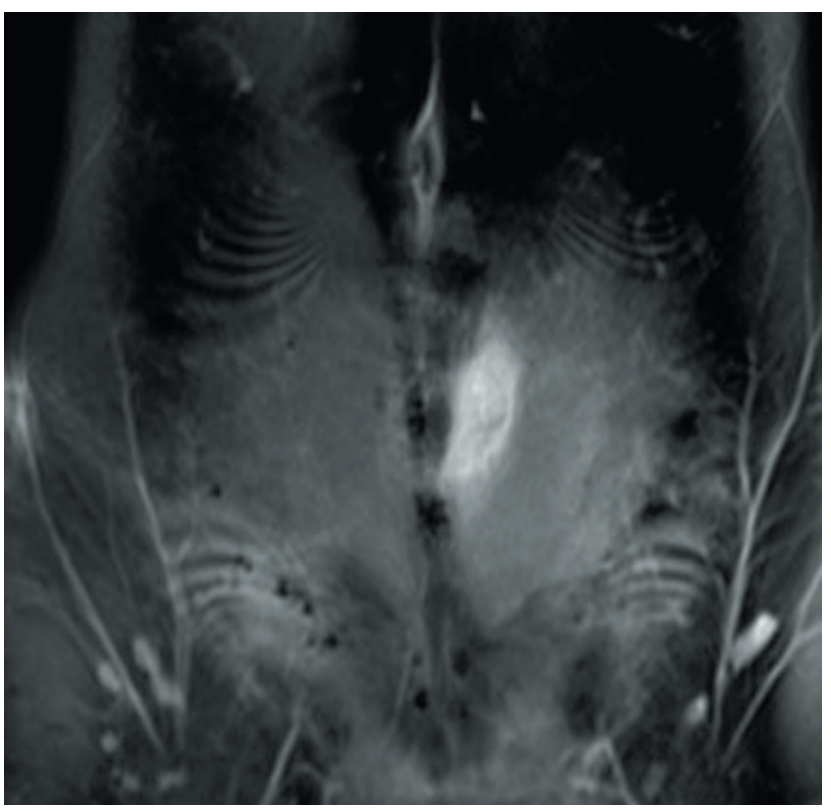

Fig. 4. Coronal post-Gd T1-weighted image. 